\title{
La censura franquista en la literatura infantil y juvenil: el caso de Sixto el pequeñín
}

\author{
The Censoring during the Franco Regime in Children's and Young \\ People's Literature: the case of Sixto el pequeñin
}

\author{
Ramón Tena Fernández \\ Universidad de Zaragoza
}

\begin{abstract}
Resumen
El tardofranquismo ha sido entendido como un periodo en el que la censura era solo un trámite administrativo. Sin embargo, obras como Censuras y LIJ en el siglo XX (2016) o La censura cultural en el franquismo (2021a) demuestran que fueron los años de mayor represión. La obra Sixto el pequeñín es un ejemplo de la dureza de los revisores. Pues, aunque el cuento estaba fechado en 1971, sus personajes eran católicos y presentaba una finalidad didáctica, se prohibieron treinta de sus cuarenta páginas. En este artículo rescatamos el informe del censor y analizamos las tachaduras del libreto original, para identificar qué se prohibió, cómo y por qué.
\end{abstract}

Palabras clave: Dictadura; Censura; Franquismo; Cuentos; Literatura infantil y juvenil
హ

\begin{abstract}
The censoring in the late period of the Franco regime was understood as a mere administrative procedure. However, works like Censuras y LIJ en el siglo XX (2016) or La censura cultural en el franquismo (2021a) proof that such period was that of greatest repression. The work Sixto el pequeñin shows an example reviewers' harshness. Despite dating from 1971, presenting its characters as catholic, and having a didactic aim, thirty out of its forty pages were censored. The present paper shows an analysis of the censor's report in which corrections in the original script have been observed as to identify what was censored, how and why.
\end{abstract}

Keywords: Dictatorship; Censoring; Franco regime; Tale; Children's and young people's literature 


\section{INTRODUCCIÓN}

El estudio de la censura franquista continúa siendo un ámbito lleno de sombras, con grandes vacíos informativos y falta de documentación que ayude a obtener una panorámica completa de lo obrado durante aquellos años. Este silencio no es por carencia de investigadores, si no por la dificultad para acceder a los legajos que se crearon durante la dictadura y por la destrucción de centenares de informes. No estamos ante una crítica frívola sino ante un hecho demostrado por uno de los principales precursores de esta tipología de estudios. Nos referimos a Abellán (1980, p. 110), el primer documentalista que consultó los legajos de la censura cuando aún se conservaban en el Ministerio de Información y Turismo (MIT). Él probó que con el traslado de estos expedientes al Archivo General de la Administración (AGA) desaparecieron más de 61.401 documentos fechados entre los años 1964 y 1969. De este expurgo acontecido en 1977 se informó al ministro Pío Cabanillas, y aunque recibió las evidencias que así lo acreditaban el investigador nunca obtuvo respuestas.

El lector de este artículo podría pensar que desde la Transición hasta la actualidad el acceso a la información ha cambiado y ahora la consulta es un proceso sencillo, ágil e incluso online; nada más lejos de la realidad. Investigaciones posteriores a Abellán (1980) como Letricidio español (2014) y Censuras y LIJ en el siglo XX (2016) exponen la dificultad para realizar trabajos basados en fuentes primarias que requieren de la lectura de estos fondos documentales ${ }^{1}$. Además, la petición de expedientes personales de quienes trabajaron como evaluadores se encuentra sujeta a tediosos procesos administrativos que hacen prácticamente imposible su investigación. Por todo ello, especialistas como Larraz (2014, p. 18) denominan a este repositorio como el archivo de la "moderna inquisición".

A consecuencia de esta realidad el investigador García (2001, p. 94) asevera que la aceptación de los lectores por series de cuentos como Celia o Cuchitifritín "ha proyectado una sombra de olvidos sobre el resto de las creaciones literarias" y el cuento breve merece una mayor atención por parte de los investigadores. Sin embargo, también debemos tener en cuenta que no ha dado tiempo a cosechar una gran amplitud de estudios con los que obtener una rica pluralidad de realidades, la dictadura concluyó en 1975 y sus informes se hicieron accesibles durante los años

\footnotetext{
${ }^{1}$ La propia estructura del archivo, sus criterios de búsqueda y descriptores no facilitan el filtrado de expedientes que afectan a las publicaciones de LIJ, ya de por sí difícil de deslindar. Además, los datos vertidos al documento electrónico actual, desde el primitivo catálogo de fichas en papel contienen numerosos errores [...] A las dificultades comentadas sobre el filtrado de datos hay que añadir la difícil accesibilidad de los expedientes por la organización de los servicios del AGA (Cerrillo y Sotomayor, 2016, pp. 36-37).
} 
ochenta. Precisamente, por cuestiones de fechas hay documentos que ni tan siquiera podemos leer, nos referimos a aquellos protegidos por la Ley de Secretos Oficiales y los que mencionan datos personales de los censores.

Pese a estas trabas administrativas existen estudios que analizan todo tipo de publicaciones. Dentro del sector periodístico destaca el análisis de Justino Sinova (2006) con La censura de prensa durante el franquismo y las declaraciones que publicó Hispania (Tena, 2019) del redactor jefe de Triunfo. Respecto a la persecución editorial es fundamental la lectura de La represión editorial durante el franquismo (Ruíz, 2008) y las memorias de Cristina Vizcaíno Auger en la Revista Chilena de Literatura (Tena, 2018). Asimismo, dentro de la censura teatral debemos mencionar el trabajo de Berta Muñoz (2006) y el análisis de Luis Matilla publicado en Tonos Digital (Tena, 2020). En esta última publicación se insiste en la necesidad de documentar la especial inquina que sufrió la literatura infantil, una labor que ha desarrollado Hanna Martens (2017) en el ámbito de las traducciones para niños, Cendán Pazos (1986) dedicado al estudio legislativo y, por último, Pedro Cerrillo y César Sánchez con la edición del libro Prohibido leer: La censura en la literatura infantil y juvenil contemporánea (2016).

En esta referencia encontramos un amplio abanico de autores que presentan trabajos desde todo tipo de perspectivas. No obstante, reseñamos tres de ellos por el estudio que ofrecen de personajes concretos y el análisis que sufrieron a causa de la censura. En lo tocante a los protagonistas varones resaltamos la contribución de Montse Pena (2016): "La censura en España de The story of Ferdinand" que expone las dificultades que tuvo que sortear su argumento para presentar como personaje principal a un toro, que lejos de destacar por la bravura y agresividad, resaltaba por su sensibilidad. En la misma línea, pero focalizando la investigación en personajes femeninos el investigador Moisés Selfa (2016) se centra en "Antoñita la fantástica y su tía Carol”, y el equipo formado por Tena, Soto y Martens (2016) en la colección Celia de Elena Fortún. Precisamente, en su capítulo "Dos modelos diferentes de escribir para niñas" revelan como la protagonista que, al inicio de la colección se caracterizaba por su inteligencia, fue tornando sus inquietudes intelectuales por otras más domésticas. La causa de esta modificación pudo estar motivada por la evolución de la censura a lo largo del Régimen y su trato hacia la LIJ. Si bien es cierto que en sus inicios estos cuentos se publicaron sin aplicar enmiendas, también lo es que en sus rediciones tuvieron que sortear objeciones importantes, de ahí la necesidad de conocer la evolución de la legislación censora. 


\section{EL CONTROL LEGISLATIVO DE LA LIJ DURANTE EL FRANQUISMO}

La revisión que Cendán Pazos (1986) realiza del Boletín Oficial del Estado demuestra que en los albores del franquismo la LIJ no contó con una atención especial. Entre otros motivos porque se consideraba un género menor y lo importante era la prensa, las alianzas internacionales y la propaganda. Su vigilancia quedó reglada de manera general a lo expuesto en la Ley de Prensa de 1938 (Ministerio de Interior, 1938). Con esta ley se aprobó un sistema de censura previa, mediante la cual no se podía editar, ni comercializar textos o grabados, cuyas galeradas no contasen con la autorización del gobierno. Sus censores tenían potestad para denegar la publicación, imponer consignas, decretar supresiones o prohibir la obra. Lo preocupante es que el lector nunca sabría qué contenido era mera propaganda y cuál procedía del imaginario del autor.

El desprecio hacia la LIJ se revierte en la década de los años cincuenta, después de la derrota de los países del Eje en la Segunda Guerra Mundial (Berta Muñoz, 2007). A partir de este momento las prioridades del Gobierno se modifican y tratan de que la imagen nacional e internacional no les vincule con el nazismo alemán y el fascismo italiano. Para ello el dictador focalizará sus políticas en tratar de conseguir un Concordato con el Vaticano. Ese acuerdo llega el 27 de agosto de 1953 y supuso una fuerte hipoteca para España, pues salvo el fin de su aislamiento internacional, no obtenía mayores beneficios (Núñez, 2014, p. 110). Durante los años de negociaciones las concesiones a la Iglesia fueron numerosas y una de ellas se hizo patente en la mayor presencia de católicos dentro de la Administración del Estado, tanto que las competencias censoras se transfirieron en 1951 a un ministerio de nueva creación, el Ministerio de Información y Turismo. Quien estuvo a cargo de esta cartera fue Gabriel Arias Salgado, una persona de exacerbado sentido religioso, reconocido por su catolicismo integrista y sus políticas inspiradas en los fundamentos de Santo Tomás (Baldo, 2006, p. 27).

Dentro de este contexto se gesta un sistema dedicado exclusivamente a la evaluación de obras para niños y el menosprecio de la década anterior se torna en atención preferente. En 1952 el Régimen crea la Junta Asesora de Prensa Infantil (Ministerio de Información y Turismo [MIT], 1952), en 1954 le asigna también la evaluación de libros y en 1955 aprueba el Reglamento de Publicaciones Infantiles y Juveniles (MIT, 1956). Este decreto es de suma importancia porque por primera vez existe una lista de temas prohibidos, se especifican sanciones y hasta se alude a un sistema de inspección. La lista de temas silenciados acapara hasta veinticinco pautas que se agrupan en cinco grandes núcleos: moral, aspectos educativos, 
calidad literaria, patria y religión. De todos ellos, el que más destaca es el ítem dedicado a la moral (Tena et al., 2019), pues mientras que el resto solo contempla tres o cuatro normas de control, este aglutina nueve indicaciones y eso obedece a que sanciona tanto los contenidos relacionados con el amor o la fisiología humana, como las acciones poco éticas (robos, mentiras, agresiones, hipocresía, venganza, alcoholismo, etc.)

Finalmente, en 1962 concluye el liderazgo de Arias Salgado y comienza el de Fraga Iribarne, cuyas intenciones se presentan muy diferentes a las de su predecesor. A él se le atribuye la defensa de la nueva Ley de Prensa e Imprenta (1966), que variaba el concepto de "censura previa", por el de "consulta voluntaria" (Jefatura del Estado, 1966). Ahora el editor no estaba obligado a someter a evaluación sus creaciones, pero cabe destacar que si no lo hacía y la obra se comercializaba con "incidencias" las sanciones eran importantes. Sin embargo, como reseñábamos al inicio de este epígrafe, la censura en las obras infantiles fue más dura que en las obras para adultos y la prueba más evidente es que la opción de la "consulta voluntaria" no fue posible para los cuentos. A las puertas de los años setenta y en plena promoción de la supuesta libertad editorial se aprueba el Estatuto de Publicaciones Infantiles y Juveniles (1967), que manifiesta firmemente que las obras para niños continúan sujetas a la censura previa y obligatoria (MIT, 1967).

\section{OBJETIVOS Y PROPUESTA DE ESTUDIOS DE CASOS}

El Estatuto de Publicaciones LIJ sustituía al Reglamento de 1955 y se caracterizaba por la ambigüedad de sus pautas y un menor número de artículos reguladores. Por consiguiente, todo quedaba a la libre interpretación del escritor que, ante el miedo de infringir alguna norma, optaba por la autocensura. Alfaya (2003, p. 45) explica que los nuevos franquistas que poblaron el ministerio de Fraga "eran gente de cuidado. Posaban de avanzados, te hacían guiños cómplices cuando en una conversación salía a relucir la censura y se permitían hablarte con ironía de los representantes más cavernícolas". Sin embargo, solo era una fachada, pues, aunque todo funcionaba pésimamente, el aparato censor continuaba activo con una mentalidad cuartelaria. De ahí la necesidad de estudiar las obras censuradas en el tardofranquismo, porque nada tenía que ver el discurso promulgado, con lo obrado internamente.

En lo que concierne a la LIJ, Cisquella et al. (1977, p. 52) concluyen que los niños no solo tuvieron tapiados los temas citados en el Estatuto, también hubo otra gran cantidad de contenidos secundarios que, pese a no estar legislados, sí tuvieron 
gran relevancia en las evaluaciones. Afirman que "las supresiones en la literatura infantil eran todavía más fantasmagóricas que en los libros para adultos”, porque detrás del deseo paternalista de proteger a la infancia se escondía la intención de "contribuir a la idiotez colectiva" (p. 121). No obstante, la única manera de identificar los temas secundarios es mediante el análisis de títulos concretos y analizar las tachaduras que recibieron. Así lo defienden trabajos internacionales como el que nos ofrece Ana María Machado (2015) con el estudio de la censura en países de Latinoamérica y el elaborado por Balça et al. (2017) acerca de la "Literatura infantil portuguesa en tiempos de dictadura".

Siguiendo estas premisas proponemos perquirir la censura del cuento Sixto el pequeñin. Su autor es Michelis Poli y fue registrado con el expediente 10125-71, por la editorial EDAF a finales del año 1971. La obra escrita para niños y juzgada por el censor 22 narra de manera realista la vida de Sixto, desde su nacimiento hasta la edad adulta, con la particularidad de que solo medía un metro y era conocido como el enano. En torno a esta característica gira todo el relato, primero se describe cómo afrontan los padres la estatura del hijo, después las reacciones de los compañeros de colegio y por último las dificultades para encontrar trabajo. La finalidad del cuento es exponer las reacciones sociales ante algo tan banal como la simple apariencia física y cómo gracias al afán de superación las metas pueden alcanzarse.

El interés por analizar esta obra se debe a su sorprendente resolución negativa, ya que tanto por su contenido como por su forma lo previsible habría sido la autorización. Esta hipótesis la formulamos tras el cotejo de más de 600 informes originales de evaluación, el cotejo de 20 expedientes personales de contratación de censores, la consulta de una decena de sentencias judiciales y la realización de entrevistas a editores, escritores e ilustradores. Gracias a este bagaje que puede consultarse de manera detallada en La censura cultural en el Franquismo (estudios y entrevistas) (Tena y Soto, 2021a) tenemos indicios suficientes para pensar que el cuento presentaba, a priori, todo lo que la censura exigía.

La editorial que ya poseía bagaje en este tipo de solicitudes presentó un argumento con personajes católicos, capítulos impregnados de moralejas y la recreación de una sociedad tan patriarcal como androcéntrica. Por tanto, según la especialista LIJ, Sotomayor Saéz (2007) la propuesta cumplía con todo lo deseable para los evaluadores del Régimen. También es importante destacar que no incorporó en las galeradas ninguna ilustración, el hecho era inusual tratándose de una obra para niños, pero recomendable para que los evaluadores no buscaran incidencias en las 
vestimentas de los personajes. Evidencia de que cumplía con todo lo necesario es que la censura aceptó el título como una obra infantil y ni tan siquiera sugirió que se destinase para adolescentes o mayores de doce años. Sin embargo, los pronósticos no se cumplieron y el libro se devolvió con una treintena de páginas censuradas de un total de cuarenta y tres. Por tanto, lo que nos atañe en este artículo es saber qué temas se eliminaron, dónde radicaba su gravedad y por qué se vetaron en plena campaña de aperturismo editorial (Fraga, 1988).

Para la consecución de estos objetivos seguiremos la secuencia metodológica que proponen los autores que hemos citado anteriormente. Pena (2016) y Selfa (2016) realizan sendos estudios de casos analizando tres factores: los personajes del cuento, la estructura espaciotemporal y la voz del narrador. Por tanto, respetaremos este itinerario perquiriendo el modelo de masculinidad que representaba el protagonista, las características de su contexto social y finalmente el vocabulario tanto del narrador como de los personajes. En esta misma línea Andrés Rábago, Premio Nacional de Ilustración, asevera que "el responsable de la censura no es el contenido silenciado sino el censor y su creación”, por tanto, antes de elaborar un análisis es oportuno rescatar la evaluación censora de la obra porque "es el censor quien decide qué significa lo que él lee” (Tena, 2018, p. 128). Por esa razón, iniciamos este estudio con la exposición del veredicto de la Administración franquista y lo concluiremos con la revelación de los atenuantes que el cuento incluyó para eludir posibles vetos.

\section{CARACTERIZACIÓN Y CONTEXTO DE SIXTO EL PEQUEÑÍN}

El censor $22^{2}$ resumió el argumento del cuento en tan solo dos líneas que no presentaban nada negativo: "Después de soportar el menosprecio y la explotación, un enano encuentra la paz de espíritu trabajando para los niños en una tienda de juguetes"3. A tenor de que lo más reseñable para el evaluador fue que el protagonista encontraba su paz espiritual, se podría vaticinar la autorización. Sin embargo, la declinó porque pensó que el contexto en el que se producían las acciones de la trama enturbiaba el desenlace. En la sección de observaciones afirma de manera

\footnotetext{
${ }^{2}$ El AGA no posibilita realizar un filtrado de libros en función de un censor concreto. Las obras no están clasificadas por evaluadores. El conocimiento de quien juzgó cada título se obtiene leyendo el informe completo de su análisis interno, donde en función del año puede acompañarse de un pseudónimo numérico (como es este caso) o de una rúbrica personal. No obstante, la biografía completa de uno de los censores identificados con el número 22 puede leerse Tena y Soto (2021b), A field open to women: censorship of children's and youth literature under Franco through women readers.

${ }^{3}$ Las citas de la evaluación del censor no aportan el número de página porque emanan de legajos sin numeración. Lo mismo sucede con algunas transcripciones del cuento, donde la versión analizada deriva de las galeradas originales, por tanto, estamos ante un libreto sin maquetar, ni encuadernar. Solo algunos capítulos incluyeron números manuscritos, por el autor o el editor.
} 
directa que "la intención educativa y religiosa de la última parte de la obra no redime en absoluto el resto de la misma e incluso del contexto total". La gravedad radica en que además de los toques groseros y necrófilos, el censor cree que en el cuento "se abusa del sarcasmo y la crueldad de las gentes hacia los enanos, y de la vergüenza que sienten algunos padres".

Por tanto, aunque autoriza la propuesta, insta a la eliminación de lo marcado en las galeradas, pues considera que, aunque "no desaparecerán del todo los posibles efectos negativos para lectores niños, sí que se atenuarán”. Ahí estaba la estrategia del tardofranquismo, en firmar licencias de edición, para dar la imagen de permisividad, pero tachando casi la totalidad de la obra o lo más relevante. De esa manera sería el propio autor el que declinase la edición, porque enmendar lo impuesto era lo mismo que crear un cuento nuevo. Además, la agrupación y clasificación que realizamos de sus tachaduras en las próximas páginas nos desvelan cuáles fueron las tres incidencias reales del cuento y, en su mayoría difieren mucho de lo expuesto en el informe.

\section{OBSERVACIONES}

Con la finalidad de hacer una exégesis exhaustiva de la obra proponemos una serie de observaciones, que en su conjunto definen la esencia del libro, y coinciden con los ítems ${ }^{4}$ juzgados por los censores en sus rúbricas: A) Cuestionamiento al modelo único de masculinidad (art. 15), B) Muestras de una sociedad superficial (art. 15), C) Vocabulario grosero (art. 18), D) Didactismo y religión (art. 14 y 16).

\section{A I Cuestionamiento al modelo único de masculinidad}

Estudios previos como el de González (2005) aclaran que el franquismo se esforzó en cultivar una imagen de hombre basada en el concepto de "monje-soldado". Es decir, personas impasibles ante la sangre vertida, pero al mismo tiempo muy católicas. Esto se tradujo en la reiteración de publicaciones de héroes españoles representados con aspecto atlético, muy esbeltos, ágiles y, por supuesto, valientes. Tal es la preocupación por resaltar la altura que se ilustran cuerpos similares a las figuras del Greco. Sin embargo, el protagonista del cuento no se asemeja en nada a este prototipo. Sus piernas eran cortas, la estatura reducida y el cuerpo no

\footnotetext{
${ }^{4}$ El reglamento 'Orientación de las publicaciones infantiles' dedica una sección a los temas de control censor: religión (Artículo 14), moral (Artículo 15), aspectos psicológicos y educativos (Artículo 16), cuestiones patriótico-políticas (Artículo 17) y factores artísticos, técnicos y literarios (Artículo 18) (Ministerio de Información y Turismo, 1956, pp. 4509-4510).
} 
musculado. Por tanto, tampoco cumplía el modelo de superhéroe americano de las publicaciones extranjeras.

Por no adecuarse a estos cánones los padres se avergüenzan de su hijo y en reiteradas ocasiones se mudan de ciudad para que nadie descubra que no crece. Lo pasean en carrito hasta los siete años, no le permiten caminar y le obligan a balbucear para simular que es un bebé. El censor no recrimina esta vida de mentira, lo que elimina es el diálogo entre los padres donde se manifiesta que están sufriendo un castigo divino, invocado por la envidia de algún compañero de trabajo. Se temía que el receptor del cuento interpretase que Dios era vengativo y que los padres de Sixto no eran buenos católicos porque no aceptaron con resignación cristiana sus designios:

¡Es un castigo del cielo! - clamaba la modista.

¡La maldición de algún colega envidioso! Gritaba el funcionario de Hacienda, tirándose del bigote.

¡Mira que tener un hijo enano, y aquí, en esta ciudad, donde todos nos conocen! ¡Yo prefiero morirme!

Calma, mujer, calma. Haré que me trasladen a otro lugar, de ese modo no sabrán que somos padres de un enano (p. 4).

Si los progenitores pensaban que era mejor morirse antes que tener un hijo enano, peores fueron las reacciones de sus compañeros de colegio. Sixto, a pesar de su inteligencia, era el centro de todas las burlas y el censor autoriza la recreación de este desprecio, pero no permite que se defienda de los ataques. El primer día de escuela un niño le pregunta si vive en el bosque, habla con lobos, es amigo de las lechuzas y vuela entre las estrellas. El protagonista se da cuenta de que lo tratan como si fuera un gnomo, pero el narrador matiza que él "era valeroso y osado a pesar de su pequeñez. Saltaba al cuello de quien intentara burlarse y solía dejarle mal parado" (p. 9). A pesar de que actúa en legítima defensa y que demuestra cómo un cuerpo diminuto puede batallar victorioso contra quienes le doblan la estatura, se insta a la eliminación de esta aclaración.

En páginas sucesivas el evaluador reitera su rechazo a la muestra de otras masculinidades, que no se reduzcan a hombres fuertes, rudos y valientes. Ejemplo de este proceder es el primer empleo que consigue Sixto, se trata de colaborar como enano en una parodia teatral de Blancanieves. Al ser una obra humorística la actriz principal, Brunilda, era una "mole de carne", con los dedos como "salchichas" y brazos semejantes a columnas dóricas. Todos estos descriptores que podían catalogarse de hirientes no recibieron ninguna objeción, el veto recayó sobre el príncipe 
que acudía al rescate. Debido al peso de Blancanieves, cuando el infante la despertó del encantamiento, no pudo alzarla en brazos y de ello se dio cuenta la caballería que le acompañaba. Seguramente el Régimen interpretó este pasaje como una ofensa a la masculinidad, porque suprimió sin paliativos como a Blancanieves ${ }^{5}$ le bastó tan solo un brazo para levantar al príncipe y con el otro dirigir el burro hasta palacio (p. 20). De esta manera se invertían los roles, el ejemplo de fortaleza y capacidad de liderazgo recaía sobre la clásica princesa debilucha y frágil, mientras que la acción del varón se reducía a la de besar.

\section{B | Muestras de una sociedad superficial y frívola}

La España franquista que se promocionaba como la "Reserva Moral de Occidente", cribó tanto de los cuentos como de las noticias las acciones indecorosas que mostraran una ciudadanía con actitudes tiranas. En este sentido, la obra que nos ocupa presentaba dos grandes debilidades: la primera es que sus personajes no eran seres mágicos, que pudieran atenuar la carga de realidad y, la segunda es que tampoco aclaraba donde acontecía lo narrado. Por consiguiente, extrapolar los sucesos al contexto de la dictadura era muy sencillo. La evidencia de este celo es que la censura prohibió que el narrador comentara que "el Estado no era nada pródigo con las familias de los funcionarios muertos" (p. 9) y aunque no se indicaba a qué gobierno aludía, la tachadura fue tajante. No hubiera sucedido nada si el autor mostrara en páginas venideras un entorno idílico, pero lo cierto es que dibujaba una sociedad impregnada de falsedad y actitudes interesadas. Tanto es así que Sixto apreció durante sus años de reclusión en el carrito de paseo que "las gentes tenían una doble manera de comportarse, según fuera en público o en privado", pues no verbalizan lo mismo cuando estaban solos ante él, que cuando se unían sus padres (p. 9).

Con el paso del tiempo el protagonista se reafirma en su creencia y como en el caso anterior, el censor tampoco permitió su publicación. Después de un par de mudanzas vivió una época dorada, a su padre le ascendieron a Inspector Jefe de Hacienda y su madre abrió una boutique muy visitada por quienes dependían de su marido. El propósito era ganarse la complicidad de la esposa y respetar al hijo, para que el inspector no cargara muchos impuestos a los negocios de las familias amigas. Sin embargo, cuando Sixto cumplió doce años el progenitor falleció y "los

\footnotetext{
${ }^{5}$ Las incidencias relacionadas con el personaje de Blancanieves son muy similares a las expuestas en los expedientes que se centraron exclusivamente en el análisis de este cuento. Los informes tanto de la censura de Salazar, como la de Franco han sido analizados en: Tena et al. (2020), La censura del cuento de Blancanieves durante las dictaduras de Franco y Salazar.
} 
que antes le sonreían y encontraban simpática su breve figura, al no necesitar ya de los buenos oficios de su padre, le miraban con hosquedad y hasta con burla, llamándole enano" (p. 9). Lo mismo sucedió con su madre que pasó de ser una referente de la moda local, con numerosa clientela, a ser una "provinciana" abocada al fracaso.

Si esta escena de doble moral no tuvo cabida, menos aún la odisea de Sixto para encontrar un empleo con el que poder vivir junto a su madre. A pesar de sus estudios como aparejador de obras, entender de materiales de construcción y tener formación contable, lo único que valoraban era la imagen que proyectaba con su cuerpo. Asiduamente quienes le entrevistaban decían: “¿un enano? ¿quieres que se burlen de mi comercio?” (p. 11); “¿un enano en una oficina?” ¿pretende codearse con gente normal? (p. 25). El protagonista perseveró tantas veces como tachaduras le impuso el censor a los desprecios que recibía, pues siempre le preguntaban “ ¿para qué sirve un enano?” y le despedían con una sonrisa irónica (p. 24).

Las únicas opciones que se le brindaron fueron aquellas relacionadas con los escenarios o los disfraces, pero siempre con un tinte burlesco. El empleo en el teatro era para despertar las risas de los asistentes y además le pagaron con un bocadillo de salchichas. El segundo fue en el circo ejerciendo de payaso y el tercero en una tienda de ropa abriendo la puerta a los niños. No obstante, pese a su educación y buenas formas su cese en la tienda se produjo después de que una señora le comentara al encargado "que hay que andar con cuidado con los enanos. Una no sabe si son niños o son hombres" (p. 27). Esta evidencia de que lo único relevante era cuidar el qué dirán se suprimió. Asimismo, se eliminó toda la crítica social que otro enano le expuso a Sixto: "Cuando tú lleves viviendo medio siglo, Sixto, comprenderás que los enanos somos criaturas segregadas por la sociedad, que se nos mira con burla y desprecio. [...] No somos criaturas humanas, constituimos una especie de defraudación de la naturaleza. Quien se arriesga a admitirnos a su lado, pronto advierte que con ello pone en peligro su reputación” (p. 21). La reflexión vetada mostraba sin eufemismos que tan repudiados eran ellos, como quienes les respetasen o trataran como a un igual.

\section{I Vocabulario grosero}

Entre la lista de incidencias que expidió el censor, la última cuestión se destinó a confirmar que existían "toques groseros" y las tachaduras revelan que dentro de este concepto se agruparon tres tipos de objeciones: los insultos, las acciones violentas y las cuestiones relacionadas con el erotismo. No obstante, no estamos ante un relato bélico, un cómic de superhéroes o una novela rosa. Por tanto, los tres 
factores son abordados de una manera muy naif e incluso en ocasiones ridícula, pero suficiente para ser tachados.

Respecto a los improperios nos encontramos supresiones de nombres de animales usados a modo de descalificativos como "ballena", para indicar gordura, "cucaracha" como ser despreciable y "perro feroz" para denominar a una persona rabiosa. Tampoco se permiten menciones como "bruja" o la expresión "por mil demonios" y aunque parezcan cuestiones superficiales realmente su gravedad era mayor que los insultos anteriores. Estudios previos como el de Tena y Soto (2019) concluyen que se represaliaron con mayor dureza porque tenían connotaciones religiosas. De hecho, el Reglamento de 1955 ya indicaba que no se podía publicar nada relacionado con el diablo o sus éxitos (art. $14 \mathrm{E}$ ). El dato curioso lo encontramos en que la censura pierde toda su intolerancia a los descalificativos cuando se dirigen al teatro, prueba de ello es que al mismo tiempo que elimina palabras como "cabezota", permite expresar que los "artistas son un hato de borregos" (p. 15) y que Sixto es un "fantochín” por ser uno de ellos.

En lo que respecta a los elementos violentos, lo primero que hemos de recordar es que estamos en los años setenta, no es una obra de los albores del franquismo donde hubiera que evitar cualquier reminiscencia de la Guerra Civil. A pesar de que hay menciones a armas, escenas truculentas o conspiraciones sanguinarias existen varias objeciones. Se elimina que Sixto "salta al cuello" de quien le insulta (p. 9), que la actriz que ejerce de Blancanieves "romperá los huesos" de quien le ataque (p. 17) y que un amigo del protagonista recibe "un puntapié en el costado" (p. 17). El resto de las supresiones recae en párrafos donde se producen pellizcos o coscorrones entre niños y cabe matizar que en su mayoría todo queda en advertencias, enfados o escenas cuya finalidad no es la agresión, es más bien algo anecdótico.

La incidencia del componente erótico afecta al único personaje femenino con diálogo, Brunilda, la actriz que trabajó con Sixto en el teatro. Hasta en cuatro ocasiones se menciona su "corsé" para indicar que los enanos le ayudaban a vestirse y cada párrafo que alude a esta prenda se veta. Menos opciones tuvo el narrador para informar que mientras se lo ponía "se palpaba el inmenso busto" y que la actriz estaba preocupada porque se desatara cuando llegara el príncipe (p. 18). Con estos descriptores no era el mejor ejemplo de mujer recatada que procuraba la censura, como tampoco lo fue el amor platónico de Sixto. Después de meses admirando en secreto a una chica alta y popularmente guapa se topó sorpresivamente con ella, y en vez de sentirse admirada, le soltó una carcajada, lo confundió con un 
niño y se burló de lo sucedido (p. 23). La censura aceptaba que un hombre rechazara un idilio amoroso porque entendía que eso demostraba su capacidad de selección, pero no era fácil que tolerara el caso inverso. Las lecturas infantiles deberían educar a las niñas para ser la perfecta casada e incluso el matrimonio se entendía como una forma de honrar al varón, pues era él quien le daba la oportunidad de sentirse realizada como mujer (Tena et al., 2016). Sixto para la censura antes que "enano" era hombre y según la ideología machista del franquismo se estaba atacando a su virilidad, con el agravante de la burla y el contexto público de la calle.

\section{I Didactismo y religión como atenuantes}

Aunque la transcripción clasificada de incidencias puede dar la sensación de que estamos ante un cuento contestario, lo cierto es que el argumento tenía un fuerte componente católico. De hecho, la solución a todos los problemas llega de la mano de un sacerdote, que le proporciona a Sixto el contacto del jefe de una tienda de juguetes. Sin embargo, antes le explica que Dios es bondadoso y que, por supuesto nunca le ha abandonado, sus desdichas se deben a que ha dejado de perseverar. Le recuerda que quien más sufrió fue Jesús y sería egoísta quejarse por problemas mundanos. Por otra parte, el encargado de la tienda, Don Pepito, es de Ávila y eso sirve al autor para recordar que de allí también era Santa Teresa, una mujer de infinita misericordia que invertía su tiempo en ayudar a los demás y que acostumbraba a cantar las verdades a la luz del alba. Este hombre, un ferviente católico acepta darle una oportunidad a Sixto, no sin antes aclararle que su única "enfermedad" es la del alma, no la estatura y que todo obedece a una prueba de Dios.

Don Pepito es la única persona que apuesta ciegamente por las capacidades del protagonista, le defiende ante los propietarios de la tienda y le da cobijo en su casa. Su estrategia pasaba por convencer a los dueños de que Sixto era lo que la juguetería necesitaba para ser un referente de éxito, pues debido a su estatura simularía ser un juguete viviente que atraería a más niños. No obstante, se ríen de la propuesta y reconocen que no pondrán en juego su prestigio contratando a un enano. Sin embargo, Don Pepito expone a los lectores que es necesario "combatir contra la necedad y la estupidez" (p. 34) y concluye que hay millones de ejemplos que demuestran como "los seres más pequeños están mejor dotados que los grandes" (p. 34) y que las cualidades de una persona no pueden ser juzgadas por el volumen de sus carnes.

Nada de esto funcionó ante la mentalidad cerril de quienes debían contratar a Sixto, por ello el defensor advirtió que si su recomendado no tenía la oportunidad que merecía, él tampoco seguiría trabajando allí. Ante esa disyuntiva los jefes 
aceptaron la propuesta y la inteligencia del protagonista hizo el resto. Cuando los padres de los niños abandonaron sus prejuicios morales, la tienda duplicó sus ventas y tal fue la confianza en su gestión que Don Pepito se retiró dejando la tienda bajo su dirección. El desenlace acredita que no se puede rechazar a nadie ante la manida excusa de que "no es normal", porque "la grandeza del universo se compone de pequeñas partículas. Cuanto más pequeñas son éstas, mayor fuerza contienen" (p. 43).

\section{CONCLUSIONES}

El análisis de las galeradas de Sixto el pequeñín y el rescate de su informe revelaban tres incidencias: los toques necrófilos, crueldad de la gente hacia los enanos y las groserías de algunos pasajes. Sin embargo, las tachaduras marcadas por el censor muestran que lo hiriente no fue lo alegado en el expediente. En primer lugar, porque el cuento lo único que tiene de necrófilo era la sección donde fallecían los padres del protagonista, y se trata de forma tan somera que ni tan siquiera el evaluador las marca. En segundo lugar, tampoco es certero indicar que molestaba especialmente la crueldad hacia los enanos, pues el rechazo a la violencia era generalizado en toda la obra, daba igual el sexo, el contexto o la estatura, la mera alusión de un verbo con connotación "agresiva" ya implicaba su veto. Además, las contadas ocasiones en las que se permite la recreación de algún daño físico, (descrito, pero no mencionado), atañe a algún enano, supuestamente el colectivo que el censor quería proteger. La tercera crítica apuntaba a la inclusión de groserías, pero ni existen insultos con palabras gruesas, ni alusiones escatológicas. Se consideran descalificativos términos muy infantiles que denotan una evaluación tan pacata como moralina.

Las debilidades reales fueron tres: la primera, la presentación de otros modelos de masculinidad que diferían del estereotipo promocionado por el Régimen, la segunda una recreación crítica de la doble moral y la tercera la facilidad de asociar todo lo negativo con el contexto sociopolítico del franquismo. Prueba de que la problemática del cuento no era el rechazo hacia Sixto si no el modelo de hombre que representaba es que, aunque el evaluador censura casi todo el relato, sí autoriza que el personaje piense de sí mismo que su apariencia es tan importante como su capacidad mental y que por ello es normal el desprecio que recibe. Además, recordemos que también se excluyen los pasajes donde hombres con cuerpos normativos necesitan de la fuerza de alguna mujer, lo cual reafirma que la auténtica objeción era exponer que ni el hombre era un ser superior, ni existía un modelo único. En lo tocante a la doble moral, su importancia era crucial porque rompía una de las 
etiquetas más defendidas por la dictadura, la autoproclamada "Reserva Moral de Occidente". Esa bandera de la moralidad se rompe al mostrar una sociedad que basa sus decisiones en dogmas, minusvalora la inteligencia, cosifica y vive más preocupada por ostentar que por ser buenas personas.

Por último, en lo que concierne a la asociación de la realidad del cuento con el contexto del país, es cierto que, en ningún momento el autor ubica las acciones en España, pero tampoco aclara lo contrario y ahí residía la incidencia, en la facilidad para extrapolar y relacionar ambas sociedades. Evidencia de ese temor es que veta la palabra "Estado" cuando se le menciona con alguna connotación negativa y que para el censor tienen más fuerza dos comentarios ambiguos sobre la Iglesia que el profundo catolicismo que manifiestan todos los personajes. Todo ello revela que, a tan solo tres años del fin de la dictadura, la censura continuaba actuando con gran firmeza y actitud cuartelaria. La diferencia con respecto a décadas anteriores es que ahora se expedía con "facilidad" la aceptación del cuento, pero imponiendo a cambio numerosísimas modificaciones que comprometían el sentido argumental de toda la obra y abocaban a su no edición.

\section{REFERENCIAS}

Abellán, M. (1980). Censura y creación literaria en España (1939-1976). Ediciones península. Alfaya, J. (2003). Crónica de los años perdidos: La España del tardofranquismo. Temas de hoy.

Balça, A., Fraga, J. \& Selfa, M. (2017). Literatura infantil portuguesa en tiempos de dictadura. Ocnos: revista de estudios sobre lectura, 16, $107-120$.

https://doi.org/10.18239/ocnos_2017.16.1.1160

Baldo, M. (2006). Excluyentes y comprensivos: la política universitaria de Ruíz - Giménez, 1951 - 1956. In J. Nieto \& J. M. Company (Ed.), Por un cine de lo real: cincuenta años después de las "Conversaciones de Salamanca" (pp. 25-35). Ediciones de la Filmoteca.

Cendán, F. (1986). Medio siglo de libros infantiles y juveniles en España (1935-1985). Pirámide.

Cerrillo, P. \& Sánchez, C. (2016). Probibido leer. La Censura en la literatura infantil y juvenil contemporánea. Universidad de Castilla-La Mancha.

Cerrillo, P. \& Sotomayor, M.V. (2016). Censuras y literatura infantil y juvenil en el siglo XX. Universidad de Castilla la Mancha.

Cisquella, G; Erviti, J.L \& Sorolla, J.A. (1977). Diez años de represión cultural: la censura de libros durante la Ley de Prensa. Anagrama

Fraga, M. (1988). Memoria breve de una vida pública. Planeta.

García, J. (2001). Así pasaron muchos años... (En torno a la literatura infantil española). Ediciones de la Universidad de Castilla la Mancha.

González, T. (2005). Monje y soldado. La imagen masculina durante el Franquismo. Revista Internacional de ciencias del Deporte, 1, 68-83.

Jefatura del Estado (1966). Ley 14/1966, de Prensa e Imprenta. BOE, 67, 3310-3315.

Larraz, F. (2014). Letricidio español: censura y novela durante el franquismo. Ediciones TREA. 
Machado, A. M. (2015). Censura, arbitrio y sus circunstancias. Ocnos: revista de estudios sobre lectura, 14, 7-17. https://doi.org/10.18239/ocnos_2015.14.01

Martens, H. (2017). Una aproximación a los estudios de traducción de literatura infantil y juvenil. Cultivalibros.

Ministerio de Información y Turismo (1952). Orden de 21 de enero de 1952 por la que se crea la Junta Asesora de la Prensa Infantil. BOE, 52, 805.

Ministerio de Información y Turismo (1956). Decreto de 24 de junio de 1955 por el que se establecen las normas a que han de ajustarse las publicaciones infantiles y juveniles. $B O E$, 204, 4509-4510.

Ministerio de Información y Turismo (1967). Decreto 195/1967, de 19 de enero, por el que se aprueba el Estatuto de Publicaciones Infantiles y Juveniles. BOE, 37, 1964-1967.

Ministerio de Interior (1938). Ley de prensa de 22 de abril de 1938. BOE, 550, 6938-6940.

Muñoz, B. (2006) Expedientes de la censura teatral franquista. Fundación Universitaria Española.

Muñoz, B. (2007). El teatro silenciado por la censura franquista. Per Abbat: boletín filológico de actualización académica y didáctica, 3, 85-96.

Núñez, S. (2014). El papel de la iglesia en la configuración del franquismo. La Albolafia: revista de Humanidades y Cultura, 1, 97-114.

Pena, M. (2016). La censura en España de The story of Ferdinand de Munro Leaf y Robert Lawson. In P. C. Cerrillo Torremocha \& C. Sánchez Ortiz (Eds.), Probibido leer: La censura en la literatura infantil y juvenil contemporánea (pp. 95-104). Universidad de Castilla La Mancha.

Ruíz, E. (2008). La represión editorial durante el franquismo. TREA.

Selfa, M. (2016). Antoñita la fantástica y su tía Cárol (1950), de Borita Casas: cuando la mujer no era un ejemplo para las niñas. In P. C. Cerrillo Torremocha \& C. Sánchez Ortiz (Eds.), Prohibido leer: La censura en la literatura infantil y juvenil contemporánea (pp. 69-74). Universidad de Castilla La Mancha.

Sinova, J. (2006). La censura de prensa durante el franquismo. Debolsillo.

Sotomayor, M. V. (2007). El humor en la literatura infantil del franquismo. Anales de literatura española, 19, 237-252. https://doi.org/10.14198/ALEUA.2007.19.14

Tena, R. (2018). Reacciones de la editorial Fundamentos ante la censura franquista. Revista Chilena de literatura, 98, 383-394. https://doi.org/10.4067/S0718-22952018000200383

Tena, R. (2018). Andrés Rábago: El censor es el que crea lo censurado. Revista de Occidente, $441,114-128$

Tena, R. (2019). La primera Ley de Prensa era una puerta totalmente cerrada que en 1966 nos abrieron para dejarnos ante un terreno lleno de trampas: Entrevista a Víctor Márquez Reviriego. Hispania: The American Association of Teachers of Spanish and Portuguese (AATSP), 102(2), 169-178. https://doi.org/10.1353/hpn.2019.0039

Tena, R. (2020). Luis Matilla y las dificultades del teatro contestario durante la censura franquista. Revista Electrónica de Estudios Filológicos: Tonos Digital, 39, SP.

Tena, R., Balça, A., Soto, J. \& Ullate M. (2020). La censura del cuento de Blancanieves durante las dictaduras de Franco y Salazar. Confluencia. Revista Hispánica de Cultura y Literatura, 36, 52-67. https://doi.org/10.1353/cnf.2020.0034

Tena, R., Ramos, A. M. \& Soto, J. (2019). Análisis comparativo de la censura de la LIJ en España y Portugal a través de la legislación promulgada durante las dictaduras de Franco y Salazar. Bulletin of Spanish Studies, 96, 1657-1679. https://doi.org/10.1080/14753820.2019.1729590 
Tena, R \& Soto, J. (2019). Las revisiones de los Cuentos de Hadas de Andersen durante la Guerra Civil y la censura franquista. En A. M. Ramos (Coord.), Tendências contemporáneas da investigação em literatura para Infância e juventude (pp. 51- 71). Tropelias \& Companhia.

Tena, R \& Soto, V. (2021a). La censura cultural en el Franquismo (estudios y entrevistas). Tirant lo Blanch.

Tena, R y Soto, J. (2021b). A field open to women: censorship of children's and youth literature under Franco through women readers. In M. Janue \& A. Presas (Eds.), Cultura y ciencia nacionales en el primer franquismo [National culture and science in early Francoism] (1939-1959) (pp. 177-196). Palgrave. https://doi.org/10.1007/978-3-030-58646-1_8

Tena, R., Soto, J., \& Martens, H. (2016). Dos modelos diferentes de escribir para niñas durante el franquismo. En P. Cerrillo \& C. Sánchez (Eds.), Prohibido leer. La censura en la Literatura Infantil y Juvenil contemporánea (pp. 65-82). Ediciones de la Universidad de Castilla la Mancha.

\section{RAMÓN TENA FERNÁNDEZ}

Es premio extraordinario de doctorado en Ciencias Sociales. Ha trabajado en diversos organismos de la Universidad de Extremadura y ha ejercido como investigador en el Palacio del Congreso de los Diputados y en el Ministerio de Educación. Actualmente es docente en la FCSH de la Universidad de Zaragoza y centra su investigación en el estudio de la censura franquista.

Tena Fernández, R. (2021). La censura franquista en la literatura infantil y juvenil: el caso de Sixto el pequeñín. Bellaterra Journal of Teaching \& Learning Language \& Literature, 14(3), e1036. https://doi.org/10.5565/rev/jtl3.1036

Rebut / Recibido / Received / Reçu: 04-04-2021

Acceptat / Aceptado / Accepted / Accepté: 08-02-2022

https://revistes.uab.cat/jt13/ 